\title{
Urine-marking and Ground-scratching by Free-ranging Arctic Wolves, Canis lupus arctos, in Summer
}

\author{
L. DAVID MECH ${ }^{1,2}$
}

${ }^{1}$ U. S. Geological Survey, Northern Prairie Wildlife Research Center, $8711-37^{\text {th }}$ Street, SE, Jamestown, North Dakota $58401-$ 7317 USA

${ }^{2}$ Mailing address: The Raptor Center, 1920 Fitch Avenue, University of Minnesota, St. Paul, Minnesota 55108 USA

Mech, L. David 2006. Urine-marking and ground-scratching by free-ranging Arctic Wolves, Canis lupus arctos, in summer. Canadian Field Naturalist 120(4): 466-470.

Urine-marking and ground-scratching were observed in an Arctic Wolf (Canis lupus) pack on Ellesmere Island, Nunavut, Canada, during 16 summers between 1986 and 2005. All previously known urination postures and ground-scratching by breeding males and females were seen, and incidence of marking and scratching was greatest when non-pack wolves were present. Observations of urine-marking of food remains supported the conclusion from a captive Wolf study that such marking signals lack of edible food.

Key Words: Arctic Wolf, Canis lupus arctos, ground-scratching, odor, scent-marking, territoriality, urine-marking, Ellesmere Island, Nunavut, Canada.

Scent-marking by Wolves (Canis lupus) includes both urine-marking and ground-scratching, usually by dominant breeding males and females (Peters and Mech 1975; Harrington and Asa 2003). Most information about Wolf urine-marking has been collected during winter by tracking Wolves in the snow (Peters and Mech 1975; Rothman and Mech 1979; Paquet and Fuller 1990; Paquet 1991; Zub et al. 2003) or during other seasons by studying captive Wolves (Harrington 1981; Raymer et al. 1984, 1986; Asa et al. 1986, 1990; Mertl-Millhollen et al. 1986; Ryon and Brown 1990; Barja and Miguel 2004). Only scattered mentions can be found of free-ranging Wolves urine-marking during summer (Clark 1971; Haber 1977; Mech 1991, 1995), and only one study of Wolf groundscratching in summer has been done (Zub et al. 2003). Detailed information about urine-marking in wild Wolves during summer is lacking because, with a few exceptions (Murie 1944; Clarke 1971; Haber 1977; Mech 1988), it has been difficult to observe Wolves in the wild during summer because of their usual fear and avoidance of humans.

I observed free-ranging Wolves in the Canadian High Arctic over a period of 20 summers, where the Wolves are highly tolerant of humans (Parmelee 1964; Miller 1978; Mech 1988). There I obtained detailed data on their urine-marking and ground-scratching behavior.

\section{Study Area}

The study area includes about $2600 \mathrm{~km}^{2}$ of the Fosheim Peninsula east, north and west of Eureka on Ellesmere Island $\left(80^{\circ} \mathrm{N}\right.$ latitude, $86^{\circ} \mathrm{W}$ longitude), Nunavut, Canada. During summer, daylight is constant. The area includes shoreline, hills, lowlands, creek bottoms and the area around Blacktop Ridge. Contrary to much of the surrounding region, this area is generally snow- and ice-free in summer, and contains rock, gravel, bare soil and scattered tundra and northern wetland vegetation. Wolves, Muskoxen (Ovibos moschatus) and Arctic Hares (Lepus arcticus) have long been common in the area (Tener 1954), and Wolves have denned there over decades or possibly centuries (Parmelee 1964; Grace 1976; Mech 1988; Mech and Packard 1990). Aside from intermittent scavenging around a weather station and military base, the main foods of the Wolves I studied were Muskoxen and Arctic Hares (Tener 1954), although seals (Phoca spp.) and Lemmings (Dicrostonyx groenlandicus) are also taken occasionally.

\section{Methods}

The Wolves I studied live far enough from exploitation and persecution by humans that they are relatively unafraid of people (Mech 1988, 1995). During 1986, I habituated a Wolf pack to my presence and reinforced the habituation each summer I observed them. The pack frequented the same area each summer and usually used the same den or nearby dens. The habituation allowed me and an associate to remain with the Wolves daily, to recognize them individually, and to watch them regularly from 10 to 200-m away, and often as close as $1 \mathrm{~m}$ (Mech 1988, 1995). This pack had disappeared by 2001, but by 2003 another pack, similarly habituated, was present (Mech 2005).

Although I made no attempt to systematically or completely record every urination or scratching made by each Wolf, I did note as many such events as I could, usually those made by breeding males and females, while I was observing general behavior. I identified breeding females by observing them nursing pups or by the presence of obvious teats. Breeding males were identified by their dominance over other males and their 
TABLE 1. Yearly distribution of observed urine marks made by breeding male (RLUs and STUs) and breeding female (FLUs and SQUs) Arctic Wolves, Ellesmere Island, Nunavut, Canada, 1986-1996, including only years in which observations covered at least four weekly periods. ${ }^{1}$

\begin{tabular}{|c|c|c|c|c|c|c|c|}
\hline \multirow[b]{2}{*}{ Summers } & \multirow{2}{*}{$\begin{array}{l}\text { Number of } \\
\text { Weekly } \\
\text { Periods }\end{array}$} & \multicolumn{2}{|c|}{ Male } & \multicolumn{2}{|c|}{ Female } & \multicolumn{2}{|c|}{ Total } \\
\hline & & Marks & $\begin{array}{c}\text { Marks } \\
\text { Per Period }\end{array}$ & Marks & $\begin{array}{c}\text { Marks } \\
\text { Per Period }\end{array}$ & Marks & $\begin{array}{c}\text { Marks } \\
\text { Per Period }\end{array}$ \\
\hline 1986 & 4 & 7 & 1.8 & 0 & 0 & 7 & 1.8 \\
\hline 1987 & 5 & 7 & 1.4 & 0 & 0 & 7 & 1.4 \\
\hline 1988 & 7 & 9 & 1.3 & 0 & 0 & 9 & 1.3 \\
\hline 1989 & 8 & 5 & 0.6 & 5 & 0.6 & 10 & 1.3 \\
\hline 1990 & 8 & 11 & 1.4 & 18 & 2.3 & 29 & 3.6 \\
\hline 1991 & 8 & 11 & 1.4 & 22 & 2.8 & 33 & 4.1 \\
\hline 1992 & 6 & 29 & 4.8 & 14 & 2.3 & 43 & 7.2 \\
\hline 1993 & 6 & 12 & 2.0 & 13 & 2.2 & 25 & 4.2 \\
\hline $1994^{2}$ & 5 & 3 & 0.6 & 5 & 1.0 & 8 & 1.6 \\
\hline 1996 & 6 & 27 & 4.5 & 14 & 2.3 & 41 & 6.8 \\
\hline
\end{tabular}

${ }^{1}$ Because of potential biases in times and methods of data collection, fine comparisons are not necessarily valid.

21995 covered only two periods.

overall initiative and control of pack activities (Schenkel 1947; Mech 1970, 1999; Peterson et al. 2002).

I collected data over periods of 1-8 weeks from June through early August 1986-2005, except 1997, 1999, 2000, and 2001. Most of the longest data collection took place 1986-1996 (Table 1). Because study periods, pack behavior, and observation emphasis varied over the summers and years (Table 2), biases in the collection of urine-marking and ground-scratching data over both the total duration of the study and over the seasonal extent of the study each summer probably affected the data collected. Thus only the data on ratios of marking postures should be unbiased enough to warrant statistical testing, and I make no attempt to draw detailed conclusions from the untested data. However, these data are still useful to make broader conclusions and to establish several facts that heretofore were unknown or poorly documented in freeranging Wolves during summer.

\section{Results}

I identified three breeding female and three breeding male Wolves, plus one pair without pups, that traveled, hunted and marked together (Mech 1995, 2005, and unpublished). I recorded males making 121 raisedleg urinations (RLU) 22 June - 8 August and 30 standing urinations (STU) 15 June - 10 August; and females, 47 flexed-leg urinations (FLU) 15 June - 3 August, and 70 squat urinations (SQU) 15 June - 29 July (Table 2). The proportion of male RLUs was significantly higher than the proportion of female FLUs $\left(\chi^{2}=45.01\right.$; $P<0.0001 ; d . f .=1)$. The number of both male and female marks I observed per weekly observation period appeared to decrease over the summer (Table 2). The number of recorded urinations per observation period varied by year from 1.3 to 7.2. (Table 1).

In addition to FLUs by breeding females, I also observed a pre-breeding female (bred the next year)
FLU twice on 6 August. An associate had also seen this animal do "slight FLUs" three times on 13 July (see Discussion.)

I observed double marking (Rothman and Mech 1979) 24 times between 26 June and 3 August. Double marking is marking of a single location by both members of a mated pair within a few minutes of each other and can be initiated by either member. Of eight possible combinations of double-marking postures (RLUs or STUs initiated by males, FLUs or SQUs initiated by females) I observed five of the combinations, with those involving RLUs and FLUs significantly predominating (Table 3).

I observed ground-scratching by both male and female breeding Wolves or by either individual as early as 15 June and as late as 31 July. The pre-breeding female (above) scratched as late as 6 August. Besides the breeders' and pre-breeder's ground-scratching, a non-breeding female was observed scratching during two different summers, the same Wolf each year. Of 16 summers when I observed breeding or mated Wolves, I recorded no scratching by them during seven of those years and three or less scratching events during six other summers.

Only during 1992, 1993, and 1996 did I see Wolves do much scratching, and both male and female breeders did so. During the above years, the breeding pair I studied, the same individuals each year, scratched regularly. Those two individuals had also been the breeders since 1989, but I saw little scratching during 19891991, 1994 or 1995. During 1992, the breeding pair scratched (and urine-marked - Table 2) much more than I had seen them in the past. They scratched (and urine-marked) especially (1) near a Muskox they had killed and at which a non-pack Wolf had also been feeding a few minutes before, (2) near a garbage dump where at least one non-pack Wolf had been feeding regularly and (3) along the easternmost location (ter- 
TABLE 2. Weekly distribution of observed urine marks made by breeding male (RLUs and STUs) and breeding female (FLUs and SQUs) Arctic Wolves, Ellesmere Island, Nunavut, Canada, 1986-2005. ${ }^{1}$

\begin{tabular}{|c|c|c|c|c|c|c|c|}
\hline \multirow[b]{2}{*}{ Summers } & \multirow[b]{2}{*}{$\begin{array}{l}\text { Number } \\
\text { Periods }\end{array}$} & \multicolumn{2}{|c|}{ Male } & \multicolumn{2}{|c|}{ Female } & \multicolumn{2}{|c|}{ Total } \\
\hline & & Marks & $\begin{array}{c}\text { Marks } \\
\text { Per Period }\end{array}$ & Marks & $\begin{array}{c}\text { Marks } \\
\text { Per Period }\end{array}$ & Marks & Per Period \\
\hline 15-22 June & 5 & 3 & 0.6 & 9 & 1.8 & 12 & 2.4 \\
\hline 23-30 June & 9 & 39 & 4.3 & 18 & 2.0 & 57 & 6.3 \\
\hline 1-7 July & 11 & 31 & 2.8 & 31 & 2.9 & 62 & 5.6 \\
\hline 8-14 July & 13 & 36 & 2.8 & 36 & 2.8 & 72 & 5.5 \\
\hline 15-21 July & 10 & 16 & 1.6 & 16 & 1.6 & 32 & 3.2 \\
\hline 22-28 July & 9 & 20 & 2.2 & 4 & 0.4 & 24 & 2.7 \\
\hline 29 July-4 August & 9 & 4 & 0.4 & 3 & 0.3 & 7 & 0.7 \\
\hline 5-10 August & 6 & 2 & 0.3 & 0 & 0 & 2 & 0.3 \\
\hline
\end{tabular}

${ }^{1}$ Because of potential biases in times and methods of data collection, fine comparisons are not necessarily valid.

ritory boundary?) where we saw them that summer. During 1996, the breeding female scratched and urinemarked while trying to force a Muskox away from the den. In another study area, in the Canadian Northwest Territories, I also observed wolves scratching several times at a Red Fox (Vulpes fulva) den (Mech unpublished) during August.

I observed ground-scratching in various elimination contexts: (1) with no other marking behavior, (2) followed by FLU or RLU, (3) preceded by FLU, RLU or SQU, (4) preceded and followed by FLU, or (5) preceded by defecation, similar to the findings of Peters and Mech (1975) and Mertl-Millhollen et al. (1986).

I also observed urine-marking in relation to food remains as Harrington (1981) also did. Breeding males and females used all four kinds of urine postures in marking uneaten food remains or prey odors including the following (1) Arctic Hare intestines; (2) chewed bones; (3) Arctic Hare stomach contents; (4) locations where regurgitated or other food had recently been eaten; (5) old kills; (6) the head of a recent Muskox kill; (7) a putrid Muskox carcass which they sometimes fed on but often passed up; (8) where another Wolf had tried but failed to catch a lemming; and (9) at caches of which they or another Wolf (including a pup) had just consumed the contents.

\section{Discussion}

Captive breeding male and female Wolves urinemark at all times of the year, with the peak frequency during the winter breeding season, and with all studies except that by Ryon and Brown (1990) observing that males tend to mark more year around than females (Peters and Mech 1975; Mertl-Millhollen et al. 1986; Asa et al. 1990; Barja and Miguel 2004).

Information on urine-marking frequencies during summer in captive wolves varies considerably. In one case, where the breeding pairs had pups, both males and females increased their marking rate during summer (Mertl-Millhollen et al. 1986). In another, where "reproductive pairs" were studied, but no pups were born, the males increased their rate of RLU during
TABLE 3. Order and type of urination postures in double urine marks ${ }^{1}$ by arctic Wolves observed during summers 1986-2005 on Ellesmere Island, Nunavut, Canada. (Males do raised-leg $[R L U]$ and standing [STU] urinations, and females, flexed-leg [FLU] and squat [SQU] urinations.)

\begin{tabular}{lc}
\hline \hline & Male Initiated \\
RLU-FLU & 6 \\
RLU-SQU & 1 \\
STU-FLU & 2 \\
STU-SQU & 0 \\
& Female Initiated \\
FLU-RLU & 9 \\
FLU-STU & 0 \\
SQU-RLU & 6 \\
SQU-STU & 0 \\
\hline \hline
\end{tabular}

${ }^{1}$ Urination sequences involving RLUs or FLUs occurred significantly more often than expected by chance $\left(\chi^{2}=6.86\right.$; $P=0.03 ;$ d.f. $=1)$.

summer, but the females did not increase their FLU rate (Barja and Miguel 2004). In two others, where no pups were involved, the RLU and FLU rates of dominant males and females reached their minimum in summer (Asa et al. 1990; Ryon and Brown 1990). Testosterone tends to decrease to a minimum during summer (Asa et al. 1990), as does testis size (Mech 2006). This relationship suggests that urine-marking, which depends on testosterone (Asa et al. 1990), would also decrease then. However, the variations found in the studies cited above suggest that the social milieu can affect the relationship between testosterone and urine-marking, so that the relationship might not always be so tight, as Asa et al. (1990) also found. Because of possible biases mentioned earlier, my data can add little to this subject, although conceivably the extreme variation seen in my data reflect actual behavioral variation similar to that reported in captive Wolves. In that respect, my data on ground-scratching are instructive.

This study documents for the first time that wild Wolves urine-mark throughout summer, using all known urine postures, including double-marking, but 
that the proportion of RLUs and FLUs to STUs and SQUs is lower then than in captive Wolves during winter (Asa et al. 1990) when RLUs and FLUs tend to predominate (Peters and Mech 1975).

The fact that a pre-breeding female was seen FLUing ("RLU" in Mech 1995) is of special interest. Based on my observation of this pack the previous three summers, I inferred that she had been born two years earlier. This pre-breeder began dominating the breeding female, her apparent mother, about the time the pre-breeder began FLUing. The pre-breeder bred the next year, apparently with her father, and remained bonded to him for the next six years, producing pups during four of them while the mother remained with the pack for two more years without being seen FLUing, and then disappeared (Mech 1995 and unpublished). This behavior of a young offspring starting to FLU or RLU and challenging its same-sex parent for dominance is similar to that seen in a captive colony (Asa et al. 1990).

Previous information about free-ranging Wolves ground-scratching in summer comes only from a single study which concluded that between April and September, ground-scratching was low and stable (Zub et al. 2003). I could make no similar seasonal comparison, but it was clear from my multi-summer observations that the degree of ground-scratching varied considerably from summer to summer, with no scratching seen some summers and regular scratching during others. In 1992, the year of most scratching, the presence of nonpack Wolves seemed to be the pertinent stimulus. It was the only year I observed the Wolves I had been studying chase or attack outsiders on three occasions (Mech 1993). It was also the year when I recorded the highest amount of urine-marking (Table 1), when the Wolves usually were extra alert and looking around intently when they marked and scratched, and when they marked their easternmost locations, suggesting a territory boundary. My impression during these times was that the Wolves were in a high state of arousal and aggressiveness. Both breeding males and females scratched about equally, contrary to Mertl-Millhollen et al. (1986) who found primarily females scratching.

Regarding marking of food remains, my observations confirm those of Harrington (1981) on captive Wolves and support his conclusion that marking of recently emptied food caches (and by extension from my observations, other inedible food remains) signals that a site contains no more edible food despite lingering odors.

In summary, this study documents that much information learned about Wolf urine-marking behavior in captivity during summer applies to free-ranging Wolves; it extends information about ground-scratching; and it places information from captive studies about urine-marking of food remains in its natural context.

\section{Acknowledgments}

This research was funded by the U. S. Geological Survey. Polar Continental Shelf Project (PCSP), Atmospheric Environment Services of Canada, and USDA North Central Research Station provided logistical support. I also thank numerous field assistants, including L. G. Adams, F. H. Harrington, W. Medwid, J. Sanders, G. Breining, and H. D. Cluff. The following reviewed the manuscript and offered helpful suggestions for its improvement: L. G. Adams, S. M. Barber, and H. D. Cluff, and M. E. Nelson. This is PCSP/EPCP paper 00905.

\section{Literature Cited}

Asa, C. S., U. S. Seal, E. D. Plotka, and L. D. Mech. 1986. Effect of anosmia on reproduction in male and female Wolves (Canis lupus). Behavioral and Neural Biology 46: 272-284.

Asa, C. S., L. D. Mech, U. S. Seal, and E. D. Plotka. 1990. The influence of social and endocrine factors on urinemarking by captive Wolves (Canis lupus). Hormones and Behavior 24: 497-509.

Barja, N. I., and F. J. Miguel de. 2004. Variation in stimulus, seasonal context, and response to urine marks by captive Iberian wolves (Canis lupus signatus). Acta Ethologica 7: 51-57.

Clark, K. R. F. 1971. Food habits and behavior of the tundra Wolf on central Baffin island. Ph.D. dissertation. University of Toronto, Toronto, Ontario, Canada. [Available from the Library and Archives Canada, Ottawa, Ontario.] 223 pages.

Grace, E. S. 1976. Interactions between Men and Wolves at an arctic outpost on Ellesmere Island. Canadian FieldNaturalist 90: 149-156.

Haber, G. C. 1977. Socio-ecological dynamics of Wolves and prey in a subarctic ecosystem. Ph.D. dissertation, University of British Columbia, Vancouver, British Columbia, Canada. 786 pages.

Harrington, F. H. 1981. Urine-marking and caching behavior in the Wolf. Behaviour 76: 280-288.

Harrington, F. H., and C. S. Asa. 2003. Wolf communication. Pages 66-103 in Wolves: Behavior, ecology, and conservation. Edited by L. D. Mech and L. Boitani. University of Chicago Press, Chicago, U.S.A. 428 pages.

Mech, L. D. 1970. The Wolf: ecology and behavior of an endangered species. Natural History Press, New York, New York, U.S.A. 389 pages.

Mech, L. D. 1988. The Arctic Wolf: living with the pack. Voyageur Press, Stillwater, Minnesota, U.S.A. 128 pages.

Mech, L. D. 1991. The way of the Wolf. Voyageur Press, Stillwater, Minnesota, U.S.A. 120 pages.

Mech, L. D. 1993. Details of a confrontation between two wild Wolves. Canadian Journal of Zoology 71: 1900-1903.

Mech, L. D. 1995. A ten-year history of the demography and productivity of an arctic Wolf pack. Arctic 48: 329-332.

Mech, L. D. 1999. Alpha status, dominance, and division of labor in Wolf packs. Canadian Journal of Zoology 77: 11961203.

Mech, L. D. 2005. Decline and recovery of a High Arctic Wolf-prey system. Arctic 58(3).

Mech, L. D. 2006. Age-related body mass and reproductive measurements of gray Wolves in Minnesota. Journal of Wildlife Management. 
Mech, L. D. and J. M. Packard. 1990. Use of Wolf den over several centuries. Canadian Field-Naturalist 104: 484-485.

Mertl-Millhollen, A. S., P. A. Goodmann, and E. Klinghammer. 1986. Wolf scent marking with raised-leg urination. Zoo Biology 5: 7-20.

Miller, F. L. 1978. Interactions between men, dogs, and Wolves on western Queen Elizabeth Islands, Northwest Territories, Canada. Musk-ox 22: 70-72.

Murie, A. 1944. The Wolves of Mount McKinley. Fauna of the National Parks of the United States. Series 5. U.S. Government Printing Office. 238 pages.

Paquet, P. C. 1991. Scent-marking behavior of sympatric wolves (Canis lupus) and coyotes (C. latrans) in Riding Mountain National Park. Canadian Journal Zoology 69: 1721-1727.

Paquet, P. C., and W. A. Fuller. 1990. Scent marking and territoriality in Wolves of Riding Mountain National Park. Pages 394-400 in Chemical Signals in Vertebrates 5. Edited by D. W. MacDonald, D. Muller-Schwarze, and S. E. Natynczuk. Oxford University Press, Oxford, England. 659 pages.

Parmelee, D. F. 1964. Myth of the Wolf. The Beaver (spring): 4-9.

Peters, R., and L. D. Mech. 1975. Scent-marking in wolves. A field study. American Scientist 63: 628-637.

Peterson, R. O., A. Jacobs, T. D. Drummer, and L. D. Mech. 2002. Leadership behavior in relation to dominance and reproductive status in gray Wolves. Canadian Journal of Zoology. 80: 1405-1412.
Raymer, J., D. Wiesler, M. Novotny, C. Asa, U. S. Seal, and L. D. Mech. 1984. Volatile constituents of Wolf (Canis lupus) urine as related to gender and season. Experientia 40: 707-709.

Raymer, J., D. Wiesler, M. Novotny, C. Asa, U. S. Seal, and L. D. Mech. 1986. Chemical scent constituents in the urine of Wolf (Canis lupus) and their dependence on reproductive hormones. Journal of Chemical Ecology 12: 297-313.

Rothman, R. J., and L. D. Mech. 1979. Scent-marking in lone Wolves and in newly formed pairs. Animal Behavior 27: $750-760$

Ryon, J., and R. E. Brown. 1990. Urine-marking in female Wolves (Canis lupus): An indicator of dominance status and reproductive state. Pages 346-400 in Chemical Signals in Vertebrates 5. Edited by D. W. MacDonald, D. MullerSchwarze, and S. E. Natynczuk. Oxford University Press, Oxford, England. 659 pages.

Schenkel, R. 1947. Expression studies of Wolves. Behavior 1: 81-129. [Translation from German by Agnes Klasson.]

Tener, J. S. 1954. A preliminary study of the Musk-oxen of Fosheim Peninsula, N.W. T. Canadian Wildlife Service Wildlife Management Bulletin Series 1, Number 9. 40 pages.

Zub, K., J. Theuerkauf, W. Jedrzejewski, B. Jedrzejewska, K. Schmidt, and R. Kowalczyk. 2003. Wolf pack territory marking in the Bialowieza Primeval Forest (Poland). Behaviour 140: 635-648.

Received 26 September 2005

Accepted 22 December 2006 